
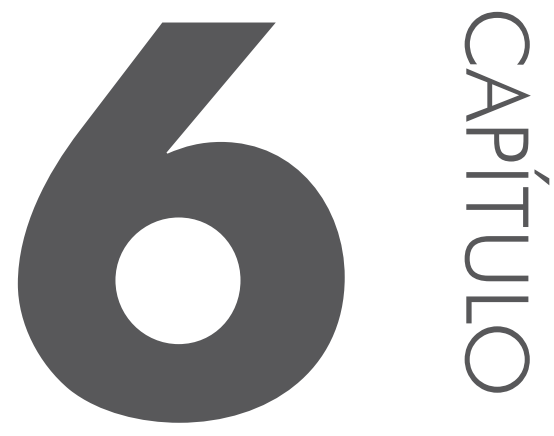

\title{
INTERAÇÃO ENTRE SEXO/GÊNERO E CLASSE SOCIAL NO USO VARIÁVEL DA CONCORDÂNCIA VERBAL
}

Livia Oushiro

\section{INTRODUC̣ÃO}

Numerosos estudos sociolinguísticos, que se basearam em amostras balanceadas quanto ao sexo/gênero do falante, verificaram uma relação recorrente entre essa variável social e diversos fenômenos de variação linguística: formas consideradas "padrão" ou "de prestígio" (como a realização velar de -ing em inglês, como em talking 'falando', ou a manutenção de /r/ 
em grupos consonantais em português, como em "proprietário") tendem a ser favorecidas pelos falantes do sexo feminino, enquanto as variantes consideradas "não padrão" ou "estigmatizadas" (como a realização alveolar de -ing [in] ou a supressão de /r/ em "propietário") tendem a ocorrer de maneira relativamente mais frequente na fala dos homens (ver, por exemplo, LABOV, 1990; 2001; CHAMBERS, 1995; CHESHIRE, 2002, PAIVA, 2004 e ROMAINE, 2003 para resenhas). Trudgill (1983:162) caracteriza tal correlação como a descoberta mais consistente dos estudos dialetais nas décadas de 1960 e 1970, e Nordberg (1971, apud ROMAINE, 2003) prevê que esse padrão seja ubíquo nas sociedades ocidentais.

Enquanto a recorrência dessa correlação certamente é digna de nota, a interpretação de tal fato é menos consensual (OUSHIRO, 2011). Dentre as diversas interpretações apresentadas, já se sugeriu que as mulheres tenderiam a empregar formas de prestígio como maneira de tentar superar sua posição desprevilegiada na sociedade (FASOLD, 1990), de não se identificar simbolicamente com a promiscuidade (GORDON, 1997), de manter a face em interações nas quais não detêm o poder (DEUCHAR, 1988), ou de adquirir status social indiretamente, ao passo que os homens podem fazê-lo por meio de sua ocupação e renda (TRUDGILL, 1972). Também já se postulou que as mulheres teriam uma maior capacidade neurobiológica para a linguagem, de modo que uma expectativa é que elas tenderiam a um domínio de uma gama maior de variantes na comunidade (CHAMBERS, 1995), posição fortemente criticada por Romaine (2003). Explicações alternativas argumentam, ainda, que não são as mulheres que favorecem as formas de prestígio, mas sim que são as formas por elas empregadas que tendem a ser vistas como "mais corretas" (MILROY et al., 1994), ou que não são as mulheres que favorecem as formas de prestígio, mas sim que são os homens que se orientariam a formas de prestígio encoberto, em geral identificadas com classes sociais mais baixas, cujo trabalho mais frequentemente braçal se relaciona simbolicamente com ideais de virilidade (CHESHIRE, 2002).

O presente trabalho discute o papel da variável sexo/gênero, a partir de uma amostra contemporânea de gravações com 118 paulistanos, em duas das variáveis mais estudadas na sociolinguística brasileira, a saber, as concordâncias verbais de número em sintagmas verbais (SVs) de primeira pessoal do plural (1PP) (por exemplo nós vamos vs. nós vai) e de terceira pessoa do plural (3PP) (por exemplo eles vão vs. eles vai). Demonstra-se que, embora as correlações observadas se aproximem dos consistentes resultados entre Sexo/Gênero e variáveis sociolinguísticas - ou seja, favorecimento das formas padrão nós vamos e eles vão por parte das mulheres -, uma análise mais detalhada da comunidade revela que seu encaixamento 
não é uniforme em todos os grupos sociais. Para 3PP, tal padrão é exacerbado na classe média baixa, mas atenuado nos extremos do continuum socioeconômico (classe alta e classe baixa). Por outro lado, para 1PP, o mesmo padrão é revertido entre as mulheres de classe mais baixa, menor nível de escolaridade e menor mobilidade geográfica. Tais fatos ressaltam a necessidade de olhar para os papéis sociais de mulheres e homens em diferentes subconjuntos da comunidade em relação aos significados sociais das variantes a fim de melhor compreender tais correlações.

Após fazer uma breve revisão de pesquisas sobre concordância verbal no português brasileiro e no português paulistano, este capítulo apresenta o corpus e os métodos empregados no presente estudo. A seção seguinte expõe os resultados de análises multivariadas tanto para 1PP quanto para 3PP, com enfoque nas correlações com sexo/gênero e em cruzamentos dessa variável com nível de escolaridade, classe social e mobilidade. O capítulo se conclui com um resumo dos resultados e com apontamentos para estudos sociolinguísticos futuros.

\subsection{A CONCORDÂNCIA VERBAL NO PORTUGUÊS BRASILEIRO E NO PORTUGUÊS PAULISTANO}

Em conjunto, os estudos sobre 1PP e 3PP já permitem traçar certas generalizações sobre a concordância verbal no português brasileiro. As taxas médias de emprego das variantes sancionadas pela norma culta variam drasticamente quando se comparam diferentes comunidades, de $30 \%$ a $100 \%$ para 1 PP e de $17 \%$ a $94 \%$ para 3 PP (ver Rubio \& Gonçalves (2012, p.1020-1024) e Lucchesi (2012, p.8) para um mapeamento mais detalhado). Os extremos desses continua são representados por falantes analfabetos ou semialfabetizados que vivem em comunidades rurais ou rurbanas, por um lado, e habitantes das capitais com nível superior de escolaridade, por outro. As variáveis $1 \mathrm{PP}$ e $3 \mathrm{PP}$ normalmente são analisadas separadamente, mas alguns poucos estudos que incluem ambas revelam que as taxas de emprego da marca explícita de número na $1 \mathrm{PP}$ costumam ser maiores do que na 3PP (ver Rodrigues (1987), para duas comunidades de favelados na periferia de São Paulo; Pereira (2004), para a fala de residentes da zona rural no interior dos estados de São Paulo e de Minas Gerais; e Rubio \& Gonçalves (2012), para a região de São José do Rio Preto-SP).

Linguisticamente, a marca explícita de número, tanto na $1 \mathrm{PP}$ quanto na 3PP, é favorecida em formas verbais cuja diferença entre o singular e o plural é mais saliente (por exemplo élsão vs. falalfalam) (NARO, 1981; NARO et al, 1999), em SVs precedidos por outros SVs com marca explí- 
cita (por exemplo, Scherre 1998; Pereira 2004), e com sujeitos [+humano] ou [+animado] (por exemplo, MONGUILHOTT, 2009; BRANDÃO; VIEIRA, 2012), pronominais (por exemplo, RODRIGUES, 1987), e imediatamente prepostos aos verbos (por exemplo, GUY 1981). Quanto à distribuição social, os estudos apresentam, em geral, quadros de variação estável (por exemplo, RUBIO, 2012) ou de mudança em progresso em direção à marca explícita (por exemplo, LUCCHESI, 2012); o primeiro se constata em comunidades urbanas e em amostras que incluem falantes de diferentes níveis de escolaridade, e o segundo em comunidades rurais e "rurbanas" - de migrantes da zona rural para áreas urbanas (BORTONI-RICARDO, 1985) - compostas de falantes menos escolarizados ou de classe social mais baixa. Em relação à escolaridade, os estudos invariavelmente apontam para o favorecimento da marca explícita quando é maior o grau de instrução do falante.

A maior parte desses trabalhos indica o favorecimento da marca explícita pelas mulheres (ver, por exemplo, GUY, 1981, NARO, 1981, PEREIRA, 2004, RUBIO; GONÇALVES, 2012), em acordo com os resultados observados em outras comunidades ocidentas e em outras línguas (LABOV, 1990; 2001), embora a variável nem sempre seja selecionada como relevante em alguns centros urbanos (ver, por exemplo, BRANDÃO; VIEI$\mathrm{RA}(2012)$ em uma amostra contemporânea do português carioca). No entanto, o padrão oposto é encontrado em comunidades de migrantes das zonas rurais para as capitais (BORTONI-RICARDO, 1985; RODRIGUES, 1987), fato que é atribuído pelas autoras à maior inserção dos homens no mercado de trabalho nas cidades para as quais migram e seu consequente contato com a norma padrão.

Na cidade de São Paulo, Rodrigues (1987) constatou tal padrão “invertido" para a $1 \mathrm{PP}$ (mas não para a 3PP, com a qual Sexo/Gênero não se mostrou correlacionada) ao analisar a fala de 40 moradores do bairro da Brasilândia, na Zona Norte da capital paulista. Os falantes foram estratificados de acordo com o sexo, dois níveis de escolaridade (nula ou primeiro grau) e três faixas etárias (20-35 anos; 36-50 anos; 51 ou mais anos), e eram oriundos de quatro espaços geográficos - São Paulo-capital; interior do estado de São Paulo e norte do Paraná; norte de Minas Gerais e sul da Bahia; nordeste. A autora assinala que, apesar de seu intuito inicial de colher amostras de fala de paulistanos, a realidade das favelas "mostrou-se bastante diferente: nelas predomina uma população de origem rural, proveniente não só do interior de São Paulo, mas de todas as regiões do Brasil” (RODRIGUES, 1987, p. 132).

Em seu estudo, o emprego da marca zero para 1PP foi de 46\% (de 693 ocorrências), 25 pontos percentuais abaixo do emprego da mesma variante 
para 3PP, que foi de $71 \%$ (de 1.356 ocorrências). Além das variáveis sociais que estratificam a amostra, sua análise multivariada para 1PP incluiu o acento da forma padrão - paroxítona (mais saliente), como em falamos/ fala, ou proparoxítona (menos saliente), como em falávamos/falava - e o tipo de sujeito (não-pronominal, pronominal explícito e pronominal não explícito); já para 3PP, a análise incluiu a posição do sujeito em relação ao verbo (imediatamente precedente, imediatamente posterior, ou distante), a saliência fônica, como em Naro (1981), e o tipo de sujeito. Quanto às variáveis sociais, Rodrigues (1987) constatou que, além de sexo/gênero, nível de escolaridade também se correlaciona somente com 1PP (com favorecimento da marca zero pelos falantes de escolaridade nula), mas não com 3PP. Os falantes provenientes do interior de São Paulo, Paraná e do Nordeste favorecem CV-0 em 1PP, e aqueles do norte de Minas Gerais e sul da Bahia favorecem CV-0 em 3PP; em ambos os casos, os paulistanos são os que menos tendem a empregar essa variante. Esta também é desfavorecida pelos falantes mais velhos, da segunda ou da terceira faixas etárias, que, segundo a autora, são os que mais sofrem a pressão normativa da comunidade mais ampla.

A partir dos padrões de variação para 1PP e 3PP e da observação etnográfica da comunidade, Rodrigues (1987) avalia que a marca zero de concordância verbal para 1PP tem significado social diferente da marca zero para 3PP: apesar de ambas serem proscritas na norma culta, o "erro" em 1 PP identifica o falante de origem rural. A autora prevê, no entanto, que as novas gerações descendentes dos migrantes, por frequentarem a escola por mais tempo, devem diferenciar seus hábitos linguísticos daqueles dos seus pais e adotar "uma variedade de língua que vai [...] refletir a estratificação social urbana" (RODRIGUES, 1987, p. 99).

Coelho (2006), aproximadamente 20 anos mais tarde, investigou a variação no emprego dos pronomes de $1 \mathrm{PP}$ (nós vs. a gente), bem como na concordância verbal (Nóis V-zero vs. Nóis V-mos), em uma comunidade de periferia também no bairro da Brasilândia, na Zona Norte de São Paulo. Com base em uma observação etnográfica, o autor construiu uma amostra de 24 entrevistas sociolinguísticas a partir de parâmetros sociais relevantes para a identificação de grupos dentro da comunidade em estudo: costureiras da cooperativa, trabalhadoras da creche, membros da associação do bairro e suas esposas, frequentadores do projeto para jovens, filhos dos membros da associação do bairro, "os mano" do gol a gol. Por ressaltar a importância de categorias locais de identidades sociais, a amostra é desbalanceada quanto ao sexo/gênero e a faixa etária dos falantes (por exemplo, todas as costureiras da cooperativa são do sexo feminino e têm mais de 25 anos, enquanto "os mano" do gol a gol são todos do sexo masculino e têm 
menos de 25 anos). Assim como no estudo de Rodrigues (1987), os falantes incluem tanto migrantes quanto seus filhos paulistanos.

$\mathrm{O}$ autor observou uma taxa de $70 \%$ de marca zero em 1PP em um total de 345 ocorrências, relativamente mais alta do que aquela observada por Rodrigues (1987) - 46\% em 693 ocorrências. Ao analisar tanto a variável "nós/a gente" quanto a concordância verbal, Coelho (2006) ressalta que o uso da marca explícita de número com o pronome nós não é a única estratégia de assimilação dos migrantes à nova realidade urbana e defende que a aprendizagem de significados sociais não se pauta somente por aqueles preconizados pela norma culta. Diferentes identidades sociais dos jovens manifestam-se linguisticamente através do emprego dos pronomes de 1PP (nós V-zero entre "os mano" e a gente V-zero entre os filhos dos membros da associação do bairro). O emprego de nós V-mos, propriamente, é privilegiado pelos adultos, sobretudo aqueles que trabalham fora do bairro. O autor ainda interpreta que não se trata da influência da escola, já que os jovens têm graus de escolaridade mais altos que os adultos de sua amostra.

Especificamente quanto ao sexo/gênero, a análise de Coelho (2006) também revela uma distribuição mais complexa das variantes na comunidade. $\mathrm{O}$ autor considerou quatro grupos de falantes quanto ao gênero: (i) homens casados e com trabalho estável; (ii) mulheres casadas e donas de casa; (iii) homens desempregados; e (iv) mães solteiras e com trabalho. Em vez de uma distribuição binária entre mulheres e homens, Coelho (2006, p. 134) verificou que a marca zero é favorecida tanto pelos homens desempregados quanto pelas mães solteiras, e desfavorecida pelos homens e mulheres casados, de "famílias estruturadas". A forma padrão, desse modo, tende a ocorrer entre os moradores de maior prestígio no bairro e com maiores expectativas de ascensão social.

O presente estudo contrasta os resultados de Rodrigues (1987) e de Coelho (2006) com aqueles de uma amostra contemporânea e mais abrangente da fala de paulistanos nativos, a fim de avaliar tendências mais amplas na comunidade. Suas considerações sobre os papéis sociais de mulheres e homens em agrupamentos de classes sociais mais baixas são fundamentais para a compreensão dos padrões que aqui se verificam.

\subsection{CORPUS E MÉTODOS}

O corpus analisado consiste em 118 entrevistas sociolinguísticas com informantes paulistanos, estratificados de acordo com seu sexo/gênero, três faixas etárias (20-34 anos; 35-59 anos; 60 anos ou mais), dois níveis de escolaridade (até Ensino Médio; Ensino Superior) e duas regiões de 
residência (bairros mais centrais; bairros mais periféricos). As gravações foram coletadas entre 2009 e 2013 pelo Grupo de Estudos e Pesquisa em Sociolinguística da USP - GESOL-USP (MENDES; OUSHIRO, 2013). As análises estatísticas foram realizadas com o programa $\mathrm{R}$ ( $\mathrm{R}$ Core Team, 2013), em modelos de efeitos mistos (fixos e aleatórios) (BAAYEN, 2008), com auxílio do pacote Rbrul (JOHNSON, 2009; ver Oushiro (2015, p.5259) para uma discussão das vantagens dos modelos de efeitos mistos em relação a programas como o GoldVarb X).

Os termos "marca zero/CV-0" e "marca explícita/CV-E" vêm sendo empregados até aqui sem maiores explicações, mas cabem alguns esclarecimentos. Tanto para $1 \mathrm{PP}$ quanto para $3 \mathrm{PP}$, são consideradas como "marca zero"/ "CV-0" as ocorrências em que o morfema de plural verbal não é realizado, que portanto coincidem com a forma de terceira pessoa do singular (foi, vai, fez etc.). Como "marca explícita"/ "CV-E", consideram-se as realizações [mos], [mo], [mu], [mus] de 1PP, e dos diversos morfemas de 3PP ([iĩ], como em crescem; [aãww̃ ] como em dão; [eruũ] ou [eru] como em cresceram etc.). Para 1PP, interessa também notar que, na presente amostra, não houve ocorrências de formas como cantemos, andemos, com alternância da vogal temática.

Excluíram-se os dados de SVs com os verbos "ter", "vir”, “por” e formas derivadas ("manter", "propor" etc.) no presente do indicativo da 3PP, pois não se distinguem fonologicamente das formas singulares (Cf. tem/têm; vem/vêm; põe/põem). Tampouco se consideram SVs com o pronome a gente; com os verbos haver e ter com sentido existencial ("tinha/ tinham muitas pessoas lá..."); sujeitos partitivos ("a maioria das pessoas foi/foram"); o chamado infinitivo flexionado opcional (CANEVER, 2012; "nós temos tudo para crescer/crescermos como nação..."); e construções impessoais como "faz/fazem dez anos". Embora a variação seja possível nesses casos, a marca zero é aquela considerada "padrão" de acordo com as gramáticas normativas (ver, por exemplo, BECHARA, 2005; CUNHA; CINTRA, 2007), de modo que não parece apropriada sua comparação com casos como "eles/nós vai".

\subsection{O ENCAIXAMENTO DE IPP E DE 3PP EM SÃO PAULO}

Seguindo-se os critérios acima, extrai-se um total de 1.150 dados de 1 PP e 10.224 de 3PP, conforme a Tabela 1 . A marca zero é relativamente infrequente no português paulistano, uma vez que corresponde a 9,4\% do total de $1 \mathrm{PP}$ e $12,6 \%$ dos dados de $3 \mathrm{PP}$. 
Tabela 1: Distribuição geral dos dados.

\begin{tabular}{c|c|c|c}
\hline & N CV-0 & N Total & \% CN \\
\hline IPP & 101 & 1.074 & 9,4 \\
3PP & 1.191 & 9.480 & 12,6 \\
\hline
\end{tabular}

Tais dados foram examinados em análises multivariadas no programa $\mathrm{R}$, separadamente para $1 \mathrm{PP}$ e para $3 \mathrm{PP}$. O conjunto de variáveis independentes analisadas, contudo, é semelhante: para ambas, incluíram-se saliência fônica (como em NARO et al (1999) para 1PP e como NARO (1981) para 3PP), paralelismo discursivo (de acordo com a presença de marca zero ou marca explícita nas cinco sentenças precedentes, com base em SCHERRE; NARO (1992), SCHERRE (1998)), posição do sujeito (imediatamente precedente, precedente e separado do verbo por 1-4 sílabas, precedente e separado do verbo por mais de 5 sílabas, posposto ao verbo), tipo de sujeito (composto por coordenação, sintagma nominal simples e pronominal) e item lexical como efeito aleatório. Para 3PP, analisou-se adicionalmente a animacidade do sujeito $([ \pm$ humano $]) .{ }^{1} \mathrm{Cada}$ análise também incluiu oito variáveis sociais: além das quatro que estratificam a amostra - sexo/gênero, faixa etária, nível de escolaridade e região de residência -, incluíram-se no modelo estatístico a classe social (a partir de índice composto por escolaridade, profissão, valor médio do metro quadrado no bairro de residência e escolaridade/profissão dos pais); a origem dos pais (São Paulo-capital, interior SP/MG, Norte/Nordeste, estrangeiros ou mista); a mobilidade geográfica (baixa: sempre morou no mesmo bairro; média: sempre morou na mesma zona; alta: mudou em diferentes zonas), bem como o falante como efeito aleatório.

Os resultados para as variáveis linguísticas replicam amplamente aquilo que já se verificou em outros estudos do português brasileiro: CV-0 tanto em 1PP quanto em 3PP é favorecida em formas verbais menos salientes (falávamos/falava ou comem/come), em sujeitos pospostos (aí iamos/ia nós, chegaram/chegou dois caras), distantes (nós com estilingue com mamona atirávamos/atirava, as pessoas lá de Goiás mesmo que vieram/veio pra cá) e não-pronominais (minha esposa e eu casamos/casou, os meus pais casaram/casou); para 3PP, a marca zero tende a ocorrer em sujeitos com o traço [-humano] (os carros não param/para) e em em SVs precedidos por outros SVs com marca zero. Desse conjunto de variáveis, não revela correlação significativa apenas paralelismo discursivo para $1 \mathrm{PP} .^{2}$

O principal interesse deste capítulo, entretanto, reside no encaixamen-

1 Para 1PP, o sujeito sempre tinha o traço [+humano].

2 Para uma descrição mais detalhada dos resultados para as variáveis linguísticas, ver Oushiro (2015), capítulo 7. 
to social das variáveis, sobretudo as correlações com sexo/gênero. Não são selecionadas como significativamente correlacionadas com $1 \mathrm{PP}$ ou com 3PP a faixa etária, a região de residência, a origem dos pais e a mobilidade. A não seleção de faixa etária indica que esses são casos de variação estável, quando se considera a comunidade como um todo. Quanto à origem dos pais, Rodrigues (1987) parece estar correta em sua avaliação de que os filhos de migrantes devem se integrar às normas da comunidade (entendidas como regras variáveis), já que seus padrões de variação não se diferenciam significativamente daqueles dos filhos de paulistanos.

Por outro lado, classe social, nível de escolaridade e sexo/gênero são selecionadas, nessa ordem, como significativamente correlacionadas à variação na concordância verbal. A variável escolaridade (Tabela 2) foi analisada separadamente de classe social, pelo fato de não serem ortogonais entre si (todos os falantes que estudaram até o Ensino Fundamental pertencem à classe média baixa). Observam-se aí tendências gradualmente maiores de emprego de CV-0 quanto menor o grau de escolarização do informante, e a diferença entre o cumprimento de cada etapa escolar (do Ensino Fundamental para o Ensino Médio, e do Ensino Médio para o Ensino Superior) é significativa tanto para $1 \mathrm{PP}$ quanto para $3 \mathrm{PP}$.

Tabela 2: Tendências de emprego de CV-0 para IPP e 3PP quanto a variáveis linguísticas.

\begin{tabular}{|c|c|c|c|c|c|c|}
\hline & \multicolumn{3}{|c|}{ IPPa } & \multicolumn{3}{|c|}{$3 \mathrm{PPb}$} \\
\hline & \multirow{2}{*}{\multicolumn{3}{|c|}{$\begin{array}{c}N \text { total }=1.074 \\
C V-0=101(9,4 \%)\end{array}$}} & \multirow{2}{*}{\multicolumn{3}{|c|}{$\begin{array}{c}N \text { total }=9.480 \\
\text { CV-0 }=1.191(12,6 \%)\end{array}$}} \\
\hline & & & & & & \\
\hline & P.R. & $\%$ & $\mathbf{N}$ & P.R. & $\%$ & $\mathbf{N}$ \\
\hline \multicolumn{7}{|l|}{ Nível de Escolaridade } \\
\hline Até Ensino Fundamental & .95 & 25,6 & 180 & .79 & 23,5 & 1.169 \\
\hline Até Ensino Médio & .60 & 10,7 & 299 & .59 & 15,7 & 3.054 \\
\hline Ensino Superior & .25 & 3,9 & 595 & .37 & 8,3 & 5.257 \\
\hline Range & 70 & & & 42 & & \\
\hline
\end{tabular}

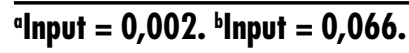

Quanto à Classe Social, verificam-se tendências gradualmente maiores de emprego de CV-0 quanto mais baixa é a classe social do falante, de .13 a .94 para 1 PP, e de .27 a .77 para 3PP (Tabela 3). Sexo/gênero também revela correlação semelhante ao verificado em outras comunidades urbanas, com o favorecimento da marca zero pelos homens (P.R. 78 e $.57)$, e desfavorecimento pelas mulheres (P.R. .16 e .44). 
Tabela 3: Tendências de emprego de CV-0 para IPP e 3PP quanto a variáveis sociais.

\begin{tabular}{|c|c|c|c|c|c|c|}
\hline & \multicolumn{3}{|c|}{ IPPa } & \multicolumn{3}{|c|}{$3 \mathrm{PPb}$} \\
\hline & \multicolumn{3}{|c|}{$\begin{array}{c}N \text { total }=1.074 \\
C V-0=101(9,4 \%)\end{array}$} & \multicolumn{3}{|c|}{$\begin{array}{c}N \text { total }=9.480 \\
\text { CV-0 }=1.191(12,6 \%)\end{array}$} \\
\hline & P.R. & $\%$ & $\mathbf{N}$ & P.R. & $\%$ & $\mathbf{N}$ \\
\hline \multicolumn{7}{|l|}{ Classe Social } \\
\hline Classe alta e média alta (A-B I) & .13 & 2,2 & 274 & .27 & 5,1 & 2.217 \\
\hline Classe media (B2) & .29 & 6,5 & 245 & .40 & 8,8 & 2.857 \\
\hline Classe média baixa (C1) & .57 & 8,7 & 311 & .61 & 17,6 & 2.515 \\
\hline Classe baixa (C2-D) & .94 & 21,3 & 244 & .77 & 20,4 & 1.891 \\
\hline Range & 81 & & & 50 & & \\
\hline \multicolumn{7}{|l|}{ Sexo/Gênero } \\
\hline Feminino & .16 & 9,0 & 466 & .44 & 10,4 & 4.826 \\
\hline Masculino & .78 & 9,7 & 608 & .57 & 14,8 & 4.654 \\
\hline Range & 62 & & & 13 & & \\
\hline
\end{tabular}

Input $=0,002 .{ }^{\text {'Input }=0,067}$.

Desse modo, quando se analisam os dados da comunidade como um todo, os resultados se assemelham àqueles "esperados" com base em estudos prévios: a marca zero é favorecida pelos menos escolarizados, pertencentes às classes mais baixas e pelos homens, tanto para 1PP quanto para 3PP.

Entretanto, cabe primeiramente assinalar que, para 1PP, a direção da correlação é inversa daquela constatada por Rodrigues (1987) na cidade de São Paulo, a partir de sua amostra que incluiu migrantes, já que a autora havia verificado favorecimento da marca zero pelas mulheres. O padrão observado entre os paulistanos nativos na presente amostra se diferencia daquele dos oriundos de outras partes, sobretudo quando de zonas rurais.

A diferença possivelmente reside nos padrões de formação de redes sociais, conforme a autora interpretou há mais de duas décadas: os homens migrantes tendem a obter trabalho fora do bairro e têm mais contato com as normas linguísticas da cidade do que as mulheres, que geralmente são donas-de-casa e mantêm laços mais estreitos com a comunidade local. Os nativos da cidade, por sua vez, não necessariamente seguem essa mesma divisão de sociabilidade entre os gêneros. Por outro lado, o estudo de Coelho (2006) havia indicado que mesmo as donas-de-casa, quando casadas com homens com emprego estável, favorecem a forma padrão em relação a homens e mulheres desempregados ou de famílias "desestruturadas”. A configuração das redes sociais dos falantes, desse modo, parece não dar conta dos padrões de uso variável das concordâncias verbais; além dela, 
parece ser necessário examinar a posição social desses falantes.

Para tanto, realizam-se cruzamentos entre o sexo/gênero dos falantes, por um lado, e seu nível de escolaridade e classe social, por outro, para os usos tanto de $1 \mathrm{PP}$ quanto de $3 \mathrm{PP}$. A Figura 1 mostra tais cruzamentos a partir das taxas de uso da variante não padrão.

\section{Figura 1: Cruzamentos entre sexo/gênero e nível de escolaridade (acima)} e classe social (abaixo), para IPP e 3PP.

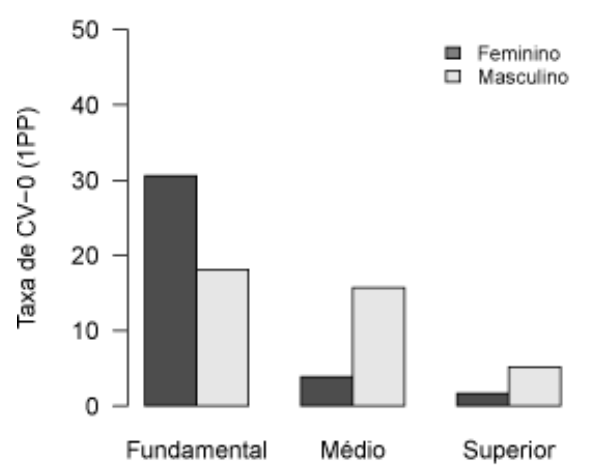

Nivel de Escolaridade

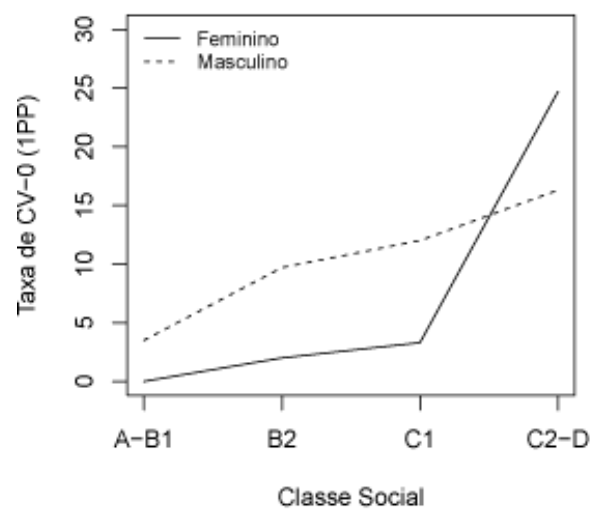

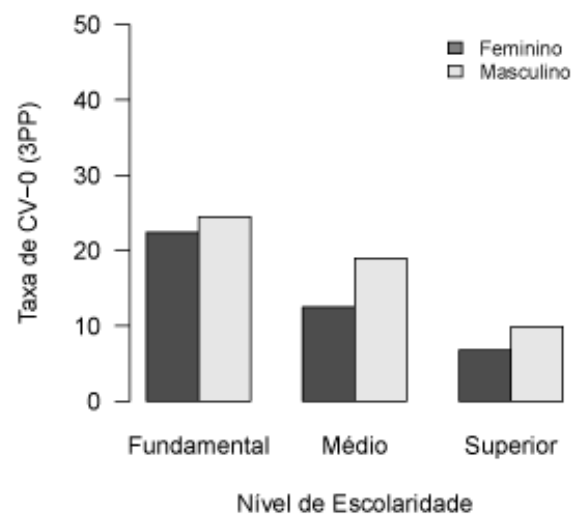

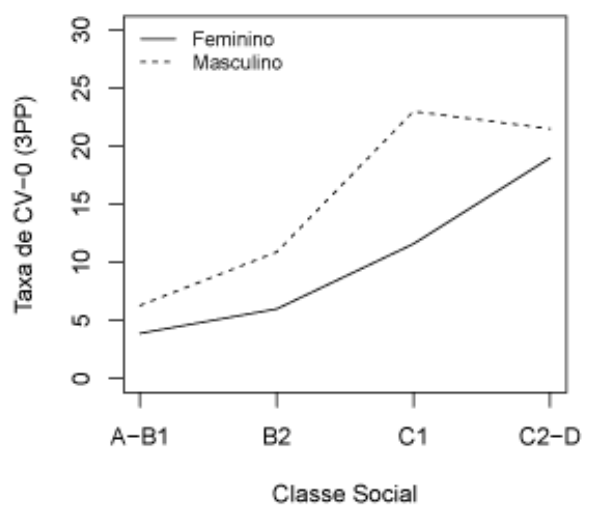

No topo da Figura 1, encontram-se os cruzamentos com nível de escolaridade para a 1PP (à esquerda) e para a 3PP (à direita). Para a 1PP, enquanto os homens (barras mais claras) com nível médio ou superior de escolaridade apresentam taxas mais altas de emprego de CV-0 do que as mulheres (barras mais escuras), entre os falantes menos escolarizados são as mulheres que favorecem a variante não padrão em relação aos homens. Para a 3PP, não existe tão "inversão" entre mulheres que estudaram até o Ensino Fundamental, mas verifica-se que a diferença entre gêneros é relativamente menor entre os de escolaridade fundamental e superior, em relação aos que estudaram até o Ensino Médio.

$\mathrm{Na}$ parte inferior da figura, observam-se padrões semelhantes no cru- 
zamento entre sexo/gênero e classe social. Para a 1PP, entre falantes de classe alta ou média (A-B1, B2 e C1), os homens (linha tracejada) apresentam taxas maiores de $\mathrm{CV}-0$ em relação às mulheres (linha contínua); no entanto, entre os paulistanos de classe mais baixa (C2-D), o padrão se inverte com o favorecimento da variante não padrão pelas mulheres. Para a 3PP, observa-se que os homens tendem a empregar a marca zero mais frequentemente do que as mulheres em todos os estratos, mas tal diferença é maior na classe média baixa (C1) e parece se neutralizar nos extremos do continuum socioeconômico (classes A-B1 e C2-D).

A partir dos quatro cruzamentos da Figura 1, depreende-se que sexo/ gênero não é uma variável independente de nível de escolaridade e de classe social; diferentemente, as variáveis interagem entre si. Duas ou mais variáveis interagem quando seu efeito conjunto na variável dependente não é previsível a partir de seus efeitos isolados (GRIES, 2013), tais como descritos nas Tabelas 2 e 3 mais acima (ainda que tais análises tenham sido multivariadas, ou seja, com a inclusão de múltiplas variáveis no modelo estatístico). A independência entre variáveis se caracteriza pelo efeito uniforme de cada uma; por exemplo, ao verificar o favorecimento da marca zero pelos homens e quanto mais baixa a classe social do falante, essas variáveis seriam independentes caso se verificasse a reprodução do padrão "mais marca zero entre homens do que entre mulheres" em todas as classes sociais, na mesma proporção. Graficamente, tal padrão se visualizaria por meio de barras ou curvas paralelas, algo que não se verifica na Figura 1.

As semelhanças entre os padrões para nível de escolaridade e classe social permitem supor que se está diante de um mesmo fenômeno, que provavelmente se refere mais propriamente ao status socioeconômico dos falantes; o efeito de escolaridade não necessariamente se deve à eficácia do sistema escolar em ensinar os valores da norma prescritiva a respeito do emprego das formas padrão de $\mathrm{CV}$, mas sim a de ampliar as possibilidades de ascensão social (por meio de melhores oportunidades de emprego, por exemplo) e, consequentemente, configurar os grupos sociais com os quais os falantes convivem cotidianamente.

Entre os falantes de classe baixa, os padrões de uso de CV-0 se assemelham àqueles do estudo de Rodrigues - favorecimento pelas mulheres para a 1PP e não diferenciação entre os gêneros para a 3PP. Trata-se portanto de padrões que ocorrem não apenas na fala de migrantes em comunidades "rurbanas", mas também na fala de nativos da grande metrópole.

Interessa também notar que a variante não padrão de 1PP é, em princípio, mais socialmente marcada do que a variante não padrão de $3 \mathrm{PP}$ (OUSHIRO, 2015). Por parte dos homens de classes mais baixas, a tendência a evitá-la em 1PP possivelmente se deve à maior consciência de seu 
estigma fora da comunidade e dentro do mercado de trabalho mais amplo - juízo de valor que não deve ocorrer na mesma medida para as variantes de 3PP. Por parte das mulheres de classes mais baixas (na presente amostra, donas de casa em sua grande maioria), a tendência a não privilegiar a forma padrão em 1PP revela sua orientação a normas da comunidade local e a menor relevância de pressões do mercado linguístico devido a seus papéis sociais. $O$ cruzamento entre sexo/gênero e mobilidade (Figura 2) vai ao encontro desse argumento: entre os falantes com menor mobilidade, que sempre viveram no mesmo bairro (e, presumivelmente, orientam-se mais favoravelmente a normas locais), são também as mulheres que favorecem a marca zero de $1 \mathrm{PP}$, diferentemente do que ocorre entre falantes com maior mobilidade, que já viveram em bairros ou zonas diferentes da cidade e que tendem a se orientar por valores das classes mais altas.

Figura 2: Cruzamento entre sexo/gênero e mobilidade para IPP.

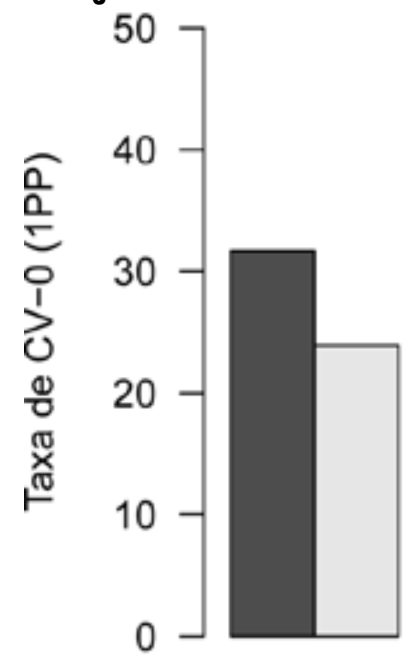

Baixa

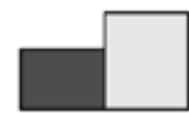

Média

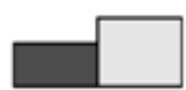

Alta

\section{Mobilidade}

Por outro lado, no caso de 3PP, a maior diferenciação de gênero na classe média e sua relativa neutralização nas classes mais altas e mais baixas já havia sido reportada em Labov $(1990,2001)$. É na classe média, sobretudo na classe média baixa, que as diferenças de gênero se fazem mais presentes. As explicações propostas para o emprego da forma padrão pelas mulheres por Fasold (1990) - como maneira de superar sua posição social desprivilegiada -, Deucher (1988) - como estratégia de manutenção da face em interações em que não detêm poder - e Trudgill (1972) - como meio de adquirir status social indiretamente, não só através de ocupação e renda - possivelmente se aplicam mais propriamente a esse estrato socio- 
econômico.

Desse modo, o exame do encaixamento social de variáveis por meio de cruzamentos permite uma descrição mais acurada e interpretações mais adequadas a processos de variação linguística. A fórmula "mulheres tendem a favorecer a forma padrão", ainda que frequentemente constatada, deve ser cuidadosamente examinada de acordo com características específicas de cada comunidade; as correlações verificadas quanto ao sexo/gênero para diferentes grupos sociais em um grande centro urbano como São Paulo evidencia que a afirmação acima se refere antes a uma hipótese do que a uma regra, que ainda demanda verificação e interpretação.

\section{CONSIDERAC̣ÕES FINAIS}

A recorrente constatação de favorecimento de formas consideradas "padrão" ou "de prestígio" por parte das mulheres em diversos estudos sociolinguísticos, sobretudo em meios urbanos, muitas vezes esconde um encaixamento social mais complexo de variáveis sociolinguísticas. Este capítulo mostra que, embora diversos padrões sociolinguísticos quanto ao uso variável das concordâncias verbais se reproduzam em São Paulo quando se considera a comunidade como um todo, a variável sexo/gênero interage com o nível de escolaridade e com a classe social dos falantes.

Esse fato reforça a necessidade de um olhar mais atento para a variável sexo/gênero, cujo efeito nem sempre pode ser interpretado por si só. As interações reportadas neste estudo possivelmente também ocorrem em outras comunidades, mas análises globais dos dados não permitem a avaliação do papel da variável em cada comunidade específica.

Ao mesmo tempo, tal interação implica a importância dos papéis sociais dos falantes na interpretação de resultados de correlações estatísticas, para além do binarismo inconsequente "mulheres favorecem a forma padrão - homens favorecem a forma não padrão". A constatação de que mulheres e homens de diferentes classes sociais exibem padrões distintos certamente conduz ao rechaço de explicações de cunho biológico ou essencialistas ("mulheres falam mais certinho") e apontam, em vez disso, para pressões do mercado de trabalho e para as tensões entre norma padrão vs. norma local, que podem mais bem explicar o papel essencial de sexo/ gênero na variação linguística. 


\section{REFERÊNCIAS}

BAAYEN, R. Harald. Analysing Linguistic Data: a Practical Introduction to Statistics. Cambridge: Cambridge University Press, 2008.

BECHARA, Evanildo. Moderna Gramática Portuguesa. Rio de Janeiro: Lucerna, 2005.

BORTONI-RICARDO, Stella Maris. The urbanization of rural dialect speakers. A sociolinguistic study in Brazil. Cambridge: Cambridge University Press, 1985. BRANDÃO, Silvia Figueiredo; VIEIRA, Silvia Rodrigues. Concordância nominal e verbal: contribuições para o debate sobre o estatuto da variação em três variedades urbanas do português. Alfa, vol. 56, n. 3, p. 1035-1064, 2012.

CANEVER, Fernanda. Evidências para um modelo de língua baseado no uso: o infinitivo flexionado em português brasileiro. Dissertação (Mestrado em Linguística). São Paulo: Universidade de São Paulo, FFLCH, 2012. $165 f$.

CHAMBERS, Jack K. Sociolinguistic theory: linguistic variation and its social significance. Oxford: Blackwell, 1995.

CHESHIRE, Jenny. Sex and Gender in Variationist Research. In: CHAMBERS, J.K.; TRUDGILL, P.; SCHILLING-ESTES, N. The Handbook of Language Variation and Change. Malden, MA: Blackwell, 2002. p. 423-443.

COELHO, Rafael F. É nóis na fita! Duas variáveis linguísticas numa vizinhança da periferia paulistana (O pronome de primeira pessoa do plural e a marcação de plural no verbo). Dissertação (Mestrado em Linguística). São Paulo, Universidade de São Paulo, FFLCH, 2006. $182 \mathrm{f}$.

CUNHA, Celso; CINTRA, Lindley. A nova gramática do português contemporâneo. $3^{\mathrm{a}}$ ed. Rio de Janeiro: Lexikon Informática, 2007.

DEUCHAR, Margaret. A pragmatic account of women's use of standard speech. In: COATES, J.; CAMERON, D. (eds.) Women in their Speech Communities. London: Longman, 1988. p. 27-32.

FASOLD, Ralph. The Sociolinguistics of Language. Oxford: Blackwell, 1990.

GORDON, Elizabeth. Sex, speech and stereotypes: why women's speech is closer to the standard. Language in Society, n. 26, p. 47-63, 1997.

GRIES, Stefan Th. Statistics for Linguistics with R: a practical introduction. Berlin/Boston: De Gruyter Mouton, 2013. 2a. ed.

GUY, Gregory R. Linguistic variation in Brazilian Portuguese: aspects of the phonology, syntax and language history. Tese (Doutorado). Filadélfia, University of Pennsylvania, 1981. $406 \mathrm{f}$.

JOHNSON, Daniel E. Getting off the GoldVarb standard: introducing Rbrul for mixed-effects variable rule analysis. Language and Linguistic Compass, vol. 3, n. 
1, p. 359-383, 2009.

LABOV, William. The intersection of sex and social class in the course of linguistic change. Language Variation and Change, vol. 2, p. 205-254, 1990.

LABOV, William. Principles of linguistic change: social factors. Oxford: Blackwell, 2001.

LUCCHESI, Dante. A concordância verbal e a polarização sociolinguística do Brasil. 2012, Ms.

MENDES, Ronald B.; OUSHIRO, Livia. Documentação do Projeto SP2010 Construção de uma amostra da fala paulistana. 2013. Disponível em $<$ http://projetosp2010.fflch.usp.br/producao-bibliografica>. Último acesso em 21/03/2014.

MILROY, James; MILROY, Lesley; HARTLEY, Sue; WALSHAW, David. Glottal stops and Tyneside glottalization: Competing patterns of variation and change in British English. Language Variation and Change 6, p. 327-58, 1994.

MONGUILHOTT, Isabel de Oliveira e Silva. Estudo sincrônico e diacrônico da concordância verbal de terceira pessoa do plural no PB e no PE. Tese (Doutorado em Linguística). Florianópolis, Universidade Federal de Santa Catarina, 2009. $229 f$.

NARO, Anthony J. The social and structural dimensions of a syntactic change. Language., vol. 57, n. 1, p. 63-98, 1981.

NARO, Anthony J.; GÖRSKI, Edair; FERNANDES, Eulália. Change without change. Language Variation and Change. vol. 11, p. 197-211, 1999.

OUSHIRO, Livia. Interpretação de padrões de covariação. Guavira Letras, vol. 13, n. 1, p. 77-88, 2011.

OUSHIRO, Livia. Identidade na pluralidade: avaliação, produção e percepção linguística na cidade de São Paulo. Tese (Doutorado em Linguística). São Paulo, FFLCH/Universidade de São Paulo, 2015. 390f.

PAIVA, Maria da Conceição de. A variável gênero/sexo. In: MOLLICA, M. C.; BRAGA, M. L. (orgs.) Introdução à sociolinguística: o tratamento da variação. São Paulo: Contexto, 2004, p. 33-42.

PEREIRA, Deize C. Concordância verbal na língua falada nas trilhas das bandeiras paulistas. Dissertação (Mestrado em Letras). São Paulo, Universidade de São Paulo, FFLCH, 2004. $116 f$.

$\mathrm{R}$ CORE TEAM. R: A language and environment for statistical computing. $\mathrm{R}$ Foundation for Statistical Computing, Vienna, Austria, 2013. Disponível em $<$ http://www.R-project.org/>. Último acesso em 21/03/2014.

RODRIGUES, Angela C. S. A concordância verbal no português popular em São Paulo. Tese (Doutorado em Letras). São Paulo, Universidade de São Paulo, FFL$\mathrm{CH}, 1987.2$ vols. $380 \mathrm{f}$. 
ROMAINE, Suzanne. Variation in language and gender. In: HOMES, J.; MEYERHOFF, M. The Handbook of Language and Gender. Oxford: Blackwell, 2003, p. $98-118$.

RUBIO, Cássio F. Padrões de concordância verbal e de alternância pronominal no português brasileiro e europeu: estudo sociolinguístico comparativo. Tese (Doutorado em Linguística). São José do Rio Preto, UNESP, IBILCE, 2012. 393 f.

RUBIO, Cássio F.; GONÇALVES, Sebastião Carlos Leite. A fala do interior paulista no cenário da sociolinguística brasileira: panorama da concordância verbal e da alternância pronominal. Alfa, vol. 56, n. 3, p. 1003-1034, 2012.

SCHERRE, Maria Marta Pereira. Paralelismo linguístico. Estudos Linguísticos, vol. 7, n. 2, p. 29-59, 1998.

SCHERRE, Maria Marta Pereira; NARO, Anthony J. The serial effect on internal and external variables. Language Variation and Change, vol. 4, p. 1-13, 1994.

SCHERRE, Maria Marta Pereira; NARO, Anthony J. Sobre a concordância de número no português falado do Brasil. In RUFFINO, G. (org.) Dialettologia, geolinguistica, sociolinguistica. (Atti del XXI Congresso Internazionale di Linguistica e Filologia Romanza) Centro di Studi Filologici e Linguistici Siciliani, Universitá di Palermo. Tübingen: Max Niemeyer Verlag, 5, 1998, p. 509-523.

TRUDGILL, Peter. Sex, covert prestige and linguistic change in the urban British English of Norwich. Language in Society, n. 1: p.179-95, 1972.

TRUDGILL, Peter. On dialect. Oxford: Blackwell, 1983. 
168 